See discussions, stats, and author profiles for this publication at: https://www.researchgate.net/publication/326781219

\title{
Ectopic BAT mUCP-1 overexpression in SKM by delivering a BMP7/PRDM16/PGC-1a gene cocktail or single PRMD16 using non-viral UTMD gene therapy
}

Article in Gene Therapy · August 2018

DOI: 10.1038/541434-018-0036-5

10 authors, including:

Shuyuan Chen

Baylor Scott \& White Health

45 PUBLICATIONS 2,132 CITATIONS

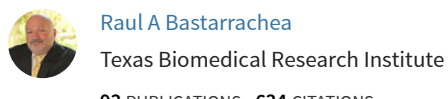

SEE PROFILE

Jin-Song Shen

Baylor Health Care System

50 PUBLICATIONS 1,092 CITATIONS

3 PUBLICATIONS 634 CITATIONS

SEE PROFILE

SEE PROFILE

Ernesto Rodriguez

Anáhuac University

47 PUBLICATIONS 896 CITATIONS

SEE PROFILE

Some of the authors of this publication are also working on these related projects:

Predictions of the risk of multifactorial diseases in healthy undiagnosed Mexican populations using validated "Online Risk Calculators" View project

echocardiography View project 


\title{
Ectopic BAT mUCP-1 overexpression in SKM by delivering a BMP7/ PRDM16/PGC-1a gene cocktail or single PRMD16 using non-viral UTMD gene therapy
}

\author{
Shuyuan Chen ${ }^{1} \cdot$ Raul A. Bastarrachea ${ }^{2,3}$ - Jin-Song Shen ${ }^{1}$ - Antonio Laviada-Nagel ${ }^{4}$ Ernesto Rodriguez-Ayala ${ }^{5}$. \\ Edna J. Nava-Gonzalez ${ }^{6}$ - Pintong Huang ${ }^{7} \cdot$ Ralph A. DeFronzo $^{8}$ • Jack W. Kent Jr. ${ }^{2,3} \cdot$ Paul A. Grayburn ${ }^{1,9}$
}

Received: 1 May 2018 / Revised: 19 June 2018 / Accepted: 28 June 2018

(c) Springer Nature Limited 2018

\begin{abstract}
Here we present our progress in inducing an ectopic brown adipose tissue (BAT) phenotype in skeletal muscle (SKM) as a potential gene therapy for obesity and its comorbidities. We used ultrasound-targeted microbubble destruction (UTMD), a novel targeted, non-viral approach to gene therapy, to deliver genes in the BAT differentiation pathway into rodent SKM to engineer a thermogenic BAT phenotype with ectopic $m U C P-1$ overexpression. In parallel, we performed a second protocol using wild-type $U c p$-1-null knockout mice to test whether the effects of the gene therapy are UCP-1 dependent. Our main findings were a robust cellular presence of $m U C P-1$ immunostaining (IHC), significantly higher expression levels of $m U C P$ 1 measured by qRT-PCR, and highest temperature elevation measured by infrared thermography in the treated thigh, achieved in rats after delivering the UTMD-PRDM16/PGC-1a/BMP7/hyPB gene cocktail. Interestingly, the weight loss obtained in the treated rats with the triple gene delivery, never recovered the levels observed in the controls in spite of food intake recovery. Our results establish the feasibility of minimally invasive UTMD gene-based therapy administration in $\mathrm{SKM}$, to induce overexpression of ectopic $m U C P-1$ after delivery of the thermogenic BAT gene program, and describe systemic effects of this intervention on food intake, weight loss, and thermogenesis.
\end{abstract}

Obesity is a common, complex, highly prevalent disorder currently affecting more than a third of the world's population [1]. Obesity is closely associated with multiple

These authors contributed equally: Shuyuan Chen, Raul A.

Bastarrachea

These authors contributed equally: Jack W. Kent Jr. Paul A. Grayburn

Paul A. Grayburn

paulgr@baylorhealth.edu

Baylor Scott \& White Research Institute, Dallas, TX, USA

2 Department of Genetics, Texas Biomedical Research Institute, San Antonio, TX, USA

3 Southwest National Primate Research Center, San Antonio, TX, USA

4 Facultad de Medicina, Universidad Autónoma de Yucatán, Yucatán, Mexico

5 Facultad de Ciencias de la Salud, Universidad Anáhuac Norte D.F, Huixquilucan, Mexico metabolic disturbances including cardiometabolic diseases [2]. Diet, exercise, and behavior modifications remain the current cornerstones of obesity treatment and prevention, even though they work very poorly for successful long-term weight loss [3]. Therefore, there is a desperate need of powerful strategies for the treatment of obesity to achieve long-term weight loss and maintenance [4]. One appealing therapeutic approach is to regulate brown adipose tissue (BAT) function [5]. BAT is the main organ of adaptive nonshivering thermogenesis (NST) in humans [6]. Brown

6 University of Nuevo Leon School of Nutrition and Public Health, Monterrey, Mexico

7 Department of Ultrasonography, The 2nd Affiliated Hospital of Zhejiang University College of Medicine, Hangzhou, Zhejiang Province, China

8 Department of Medicine, Division of Diabetes, University of Texas Health Science Center and Texas Diabetes Institute, University Health System, San Antonio, TX, USA

9 Department of Internal Medicine, Division of Cardiology, Baylor Scott \& White Heart and Vascular Institute, Baylor University Medical Center, Dallas, TX, USA 
adipocytes have a high mitochondrial content that contains a specialized protein (mUCP-1) that causes a proton leak across the inner membrane of the mitochondria, thereby dissipating energy in the form of metabolic heat [7]. Ectopic expression of UCP1 in SKM of transgenic (Tg) mice has been shown to result in a phenotype characterized by increased energy expenditure, reduced body weight, reduced fat mass, improved glucose tolerance [8], decreased muscle energy efficiency, and altered substrate oxidation [9], as well as increased longevity [10].

Metabolic diseases such as obesity are particularly attractive candidates for gene therapy [11]. Numerous successful studies have used viral vectors for gene therapy [12] but viral vectors present significant biosafety concerns [13]. A recent non-viral delivery alternative is ultrasoundtargeted microbubble destruction (UTMD) [14]. This sitespecific approach infuses a transgene precoupled to gas-filled lipid microbubbles that are burst within the microvasculature of the target tissue via an ultrasound (US) signal, resulting in DNA release and transfection of neighboring cells within the tissue [15]. Our group is actively engaged in developing optimal tissue-specific UTMD techniques for gene transfection [16], which we have applied to cardiometabolic disorders in rodents and nonhuman primates. This work has included UTMD delivery of genes in the differentiation pathway of pancreatic $\beta$-cell function in both rats [17] and baboons [18, 19] to reverse streptozotocin-induced $\beta$-cell destruction and diabetes. Previous work has also documented that UTMD delivery of adiponectin to SKM enhanced serum adiponectin levels and improved hepatic insulin resistance, showing that UTMD efficiently delivered the adiponectin gene to skeletal muscle (SKM) improving insulin sensitivity and glucose homeostasis [20].

To address BAT-mediated approaches to obesity, we recently conducted a small proof-of-concept study to show that by administering tissue-specific UTMD gene therapy, we could obtain overexpression of mUCP-1 in the SKM of obese Zucker ZDF fa/fa rats. BAT and SKM cells share common precursors, and BAT is developmentally closer to SKM than to white adipose tissue (WAT) [21]. We therefore treated rat SKM via UTMD with plasmids driving $B M P 7 /$ PRDM16/ PPARGC1A genes - part of the gene cascade that induces BAT differentiation and expression of UCP-1. Controls received plasmids driving the DsRed reporter gene. Despite the small number of animals available for our pilot, we found that the administration of the gene cocktail to SKM in this rat model of genetic obesity engineered a BAT phenotype with $m U C P-1$ overexpression [22].

For this study, our aims were (a) to replicate and further characterize our previous findings [22] in a larger cohort of wild-type rodents through UTMD delivery of a cocktail of thermogenic BAT genes (BMP7, PRDM16 and PGC-1a) to
SKM to induce ectopic mUCP-1 overexpression and thermogenesis; (b) to document if the results obtained with the cocktail of thermogenic BAT genes may offer some advantage when compared with delivery of PRDM16 alone; and (c) to test our gene therapy protocol in $U C P-1$ null knockout mice to determine if the effects of the intervention are UCP-1 dependent, as expected.

\section{Results}

\section{Study design}

Protocol-1: A total of 24 wild-type Sprague-Dawley rats received: (1) UTMD with pXL-BSII-CI-DsRed/hyPB plasmids (controls, $n=6$ ); (2) UTMD with pCMVPRDM16 plasmid $(n=6)$; (3) UTMD with pXL-BSII-CIPRDM16/hyPB plasmids, and (4) UTMD with PRDM16/ $P G C-1 \alpha / B M P 7 /$ hyPB plasmids $(n=6)$. Protocol-2: A total of 30 C5BL/6 mice received: (1) WT mice: UTMD-pXLBSII-DsRed/hyPB $(n=10)$; (2) WT mice: UTMD-pXLBSII-CI-PRDM16/hyPB $(n=10)$, and (3) $m U C P-1^{-/-}$ko mice: UTMD-pXL-BSII-CI-PRDM16/hyPB $(n=10)$.

\section{Food intake changes}

We fed rats with access to $20 \mathrm{~g} /$ day and mice with $3.5 \mathrm{~g}$ /day of a rodent high-fat diet for 1 month before performing UTMD gene delivery and then continued feeding with the same diet 1 month after UTMD procedures. The rats were eating $\sim 94 \mathrm{Kcal} /$ day and the mice $\sim 16.5 \mathrm{Kcal} /$ day on the high-fat diet $(4.73 \mathrm{Kcal} / \mathrm{g})$ before the gene therapy. Figure 1a shows that food intake in rats (Protocol-1) sharply decreased in all animals within the first 3 days to $2-4 \mathrm{~g}$ (UTMDPRDM16/hyPB or UTMD-PRDM16/PGC-1 $/$ /BMP7/hyPB), to 6-12 $\mathrm{g}$ (UTMD-pCMV-PRDM16), and to $16-18 \mathrm{~g}$ in the UTMD-DsRed/hyPB controls. Rats from all groups gradually increased their daily food intake between days 4 and 10 , recovering the intake levels prior to UTMD gene therapy by day 20. Figure $1 \mathrm{~b}$ shows that Protocol-2 mouse food intake also sharply decreased to $1 \mathrm{~g}$ after WT or UCP-1-/- ko mice received UTMD-PRDM16/hyPB. Both groups recovered their daily food intake between days 3 and 10 , with a sharper increase in the UCP-1-/- ko mice. The group receiving UTMD-PRDM16/hyPB steadily kept their food intake after day 4 in $2.5 \mathrm{~g}$ until day 30 . WT mice receiving UTMDDsRed/hyPB slightly decreased their food intake to $2.5 \mathrm{~g}$ and immediate recovered pre-UTMD administration levels.

\section{Weight and fat loss}

In the rat model (Fig. 1c), body weights were not significantly different at baseline $(\sim 550 \mathrm{~g}$, day 0$)$. There was an 


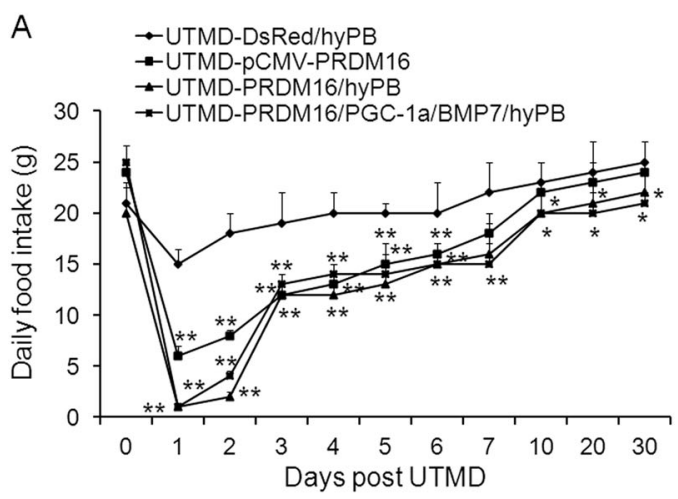

B
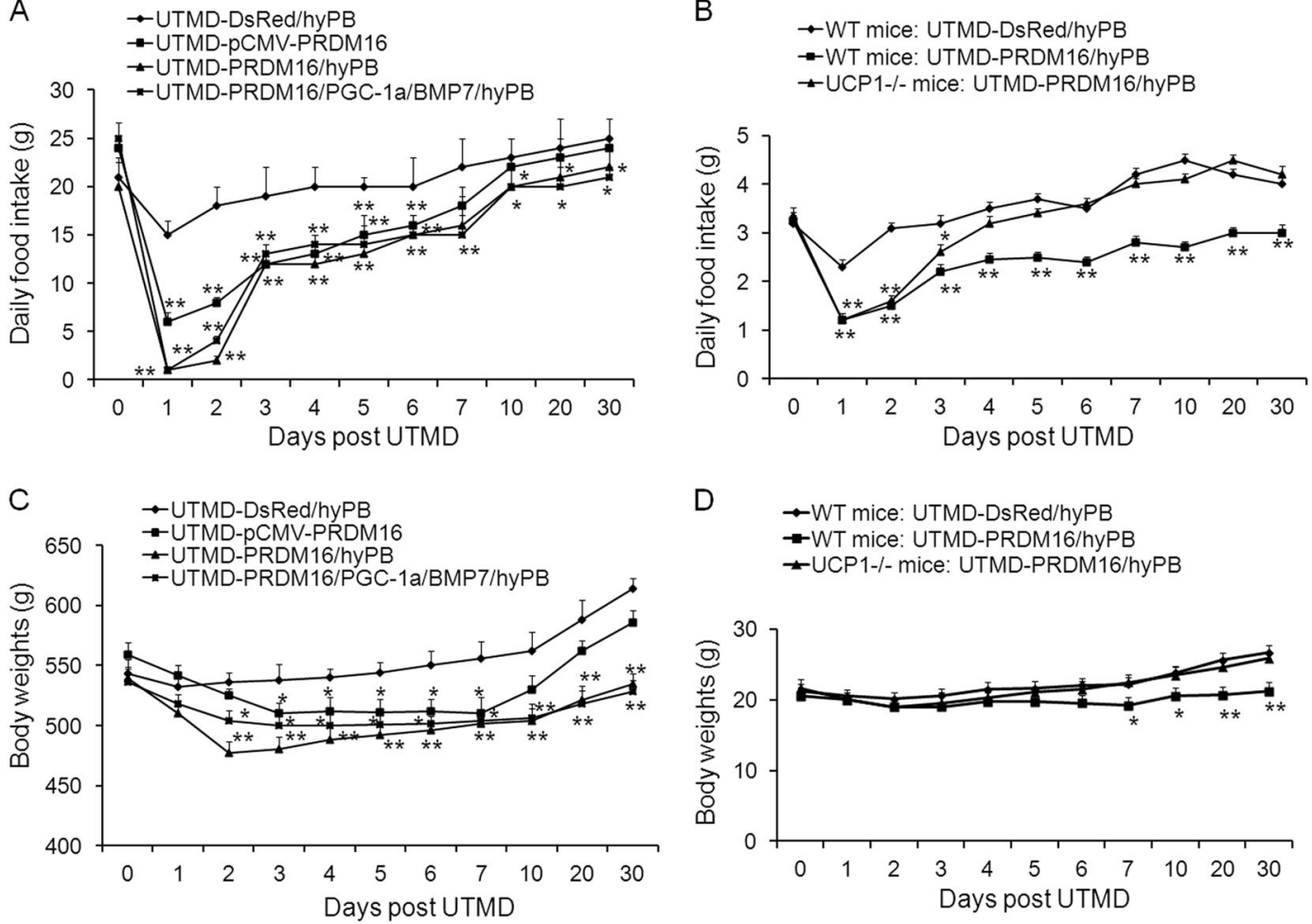

D

$\rightarrow$ WT mice: UTMD-DsRed/hyPB

-WT mice: UTMD-PRDM16/hyPB

-UCP1-/- mice: UTMD-PRDM16/hyPB

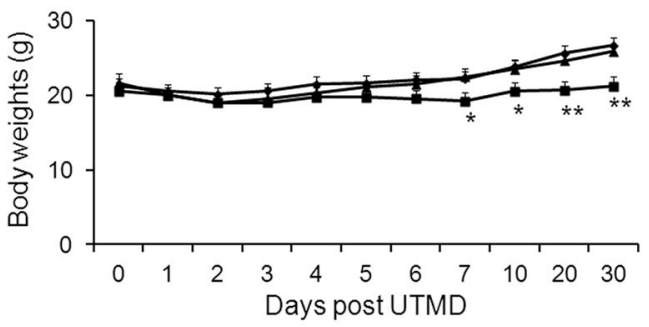

rat body weights (grams). Values are presented as mean \pm SEM, $n=6$ per group; * $p<0.05, * * p<0.001$ vs DsRed control groups. d A graphic for mice body weights (grams). Values are presented as mean \pm SEM. $n=10$ per group; ${ }^{*} p<0.05,{ }^{* *} p<0.001$ vs control groups

\section{Thermogenesis measured through infrared technology}

We measured temperature changes [23] in both rodent models, using an infrared digital thermographic camera [24] and found that their temperature increased in the targeted local left thigh area when compared with the right thigh control at 14 days or 28 days post UTMD gene delivery ( $p$ $<0.05$ vs control thighs or DsRed group) (Fig. 2c, d).

\section{Overexpression of mUCP-1 in the rat model}

We expected the gene cocktail or PRDM16 alone to induce mUCP-1 overexpression in the targeted SKM area because mUCP-1 is their direct downstream gene product. Immunohistochemistry (IHC) from Fig. 3 shows that a remarkable mUCP-1 signal was detected in rat SKM cells 1 month after UTMD-pXL-BASII-CI-PRDM16/BMP7/PGC-1 $\alpha$ gene cocktail was delivered to the site-specific left thighs (Fig. 3g), also detected in lesser intensity in the UTMDpXL-BASII-CI-PRDM16/hyPB (Fig. 3e), but it was not seen in the right thigh controls (Fig. 3f-h) nor in the controls treated with the UTMD-DsRed reporter gene (Fig. 3a, b). 0.05 vs DsRed control group, $n=10$ ) (Fig. 1d). 

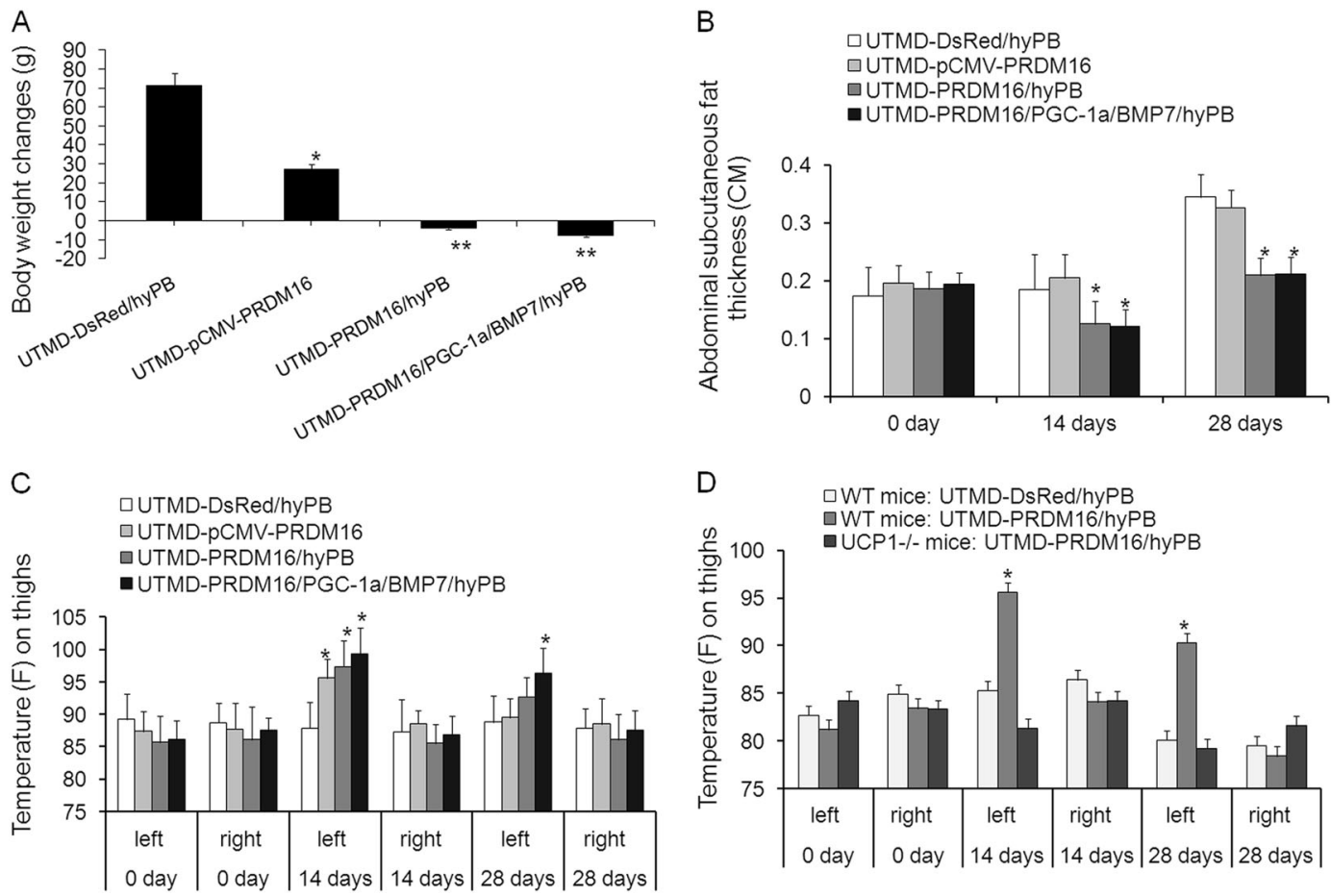

Fig. 2 a A graphic for rat body weight changes (grams). Values are presented as mean \pm SEM, $n=6$ per group; $* * p<0.001$ vs DsRed control groups. b A graphic for the thickness of the abdominal subcutaneous fat layer, Values are presented as mean $\pm \mathrm{SEM}, n=6$ per group; * $p<0.05$ vs control groups. c A graphic for temperature $(\mathrm{F})$ on

rat thighs. Values are presented as mean \pm SEM, $n=6$ per group; ${ }^{*} p<$ 0.05 vs control groups. $\mathbf{d}$ A graphic for temperature $(\mathrm{F})$ on mice thighs. Values are presented as mean $\pm \mathrm{SEM}, n=10$ per group; $* p<0.05$ vs control groups

mUCP-1 signal was significantly decreased in the regular CMV promoter driving the PRDM16 plasmid group (Fig. 3c). The results of the mUCP-1 quantitative reverse transcriptase-PCR (qRT-PCR) gene expression (Fig. 3i) shows that mUCP-1 complementary DNA (cDNA) levels in the treated left thigh after UTMD-pXL-BASII-CI-PRDM16/ $B M P 7 / P G C$ - $1 \alpha$ gene cocktail were $36 \pm 9$-fold greater than UTMD-pXL-BASII-CI-PRDM16/hyPB alone (18 \pm 3 -fold; $p<0.001)$.

\section{PRMD16 signal in rat SKM after UTMD gene delivery}

We measured PRDM16 IHC and expression with both $\mathrm{CMV}$ promoter-driven plasmids and hyPB transposon plasmids in our UTMD gene delivery system. IHC from Fig. 3 also shows that a significant rat PRDM16 signal was detected in SKM cells 1 month after UTMD-pXL-BASIICI- PRDM16/hyPB or PRDM16/BMP7/PGC-1 $\alpha$ gene cocktail delivered to the left thighs (Fig. 3n-p) but was not detected in the right thigh controls (Fig. 3o-q), nor in the controls treated with UTMD-DsRed reporter gene (Fig. 3j, k). Moreover, PRDM16 signal was very weak in the regular CMV promoter driving the PRDMI6 plasmid group (Fig. 31). PRMD16 qRT-PCR gene expression showed a level of $76 \pm 4$-fold and $82 \pm 8$-fold after UTMDpXL-BASII-CI-PRDM16/BMP7/PGC-1 $\alpha$ gene cocktail and

UTMD-pXL-BASII-CI-PRDM16/hyPB, respectively $(p<$ 0.001) (Fig. 3r).

\section{mUCP-1 and PRMD16 signal in mice SKM after UTMD gene delivery}

In the mouse model, we observed robust expression of mUCP-1 in wild-type, but not in $m U C P-1-/-$ ko mice after UTMD-pXL-CI-PRDM16/hyPB. IHC from Fig. 4 shows that a mUCP-1 signal only existed in the treated left thigh from WT mice (Fig. 4c) but it was not seen in $m U C P-1-/-$ ko mice and right thigh controls (Fig. 4d, e), nor in the controls treated with UTMD-DsRed reporter gene (Fig. 4a). qRT-PCR results show that mUCP-1 cDNA levels in the treated thigh of the WT mice group after UTMD-pXLBASII-CI- PRDM16/hyPB was, as expected, $45 \pm 4$-fold greater than in the thigh of the $m U C P-1-/-$ knockout mice group $(p<0.001)$. It also showed no difference between treated and control thigh in the $m U C P-1-/-$ knockout mice (Fig. 4g). We also achieved decent overexpression of PRDM16 in either the wild-type or UCP-1-/- knockout mice. IHC from Fig. 4 shows that PRDM16 signal only existed in the treated left thigh in WT mice or $m U C P-1-/-$ ko mice (Fig. 4j-1) but are not seen in right thigh controls (Fig. 4j-1), nor in the controls treated with UTMD-DsRed reporter gene (Fig. 4k-m). qRT-PCR results show that 

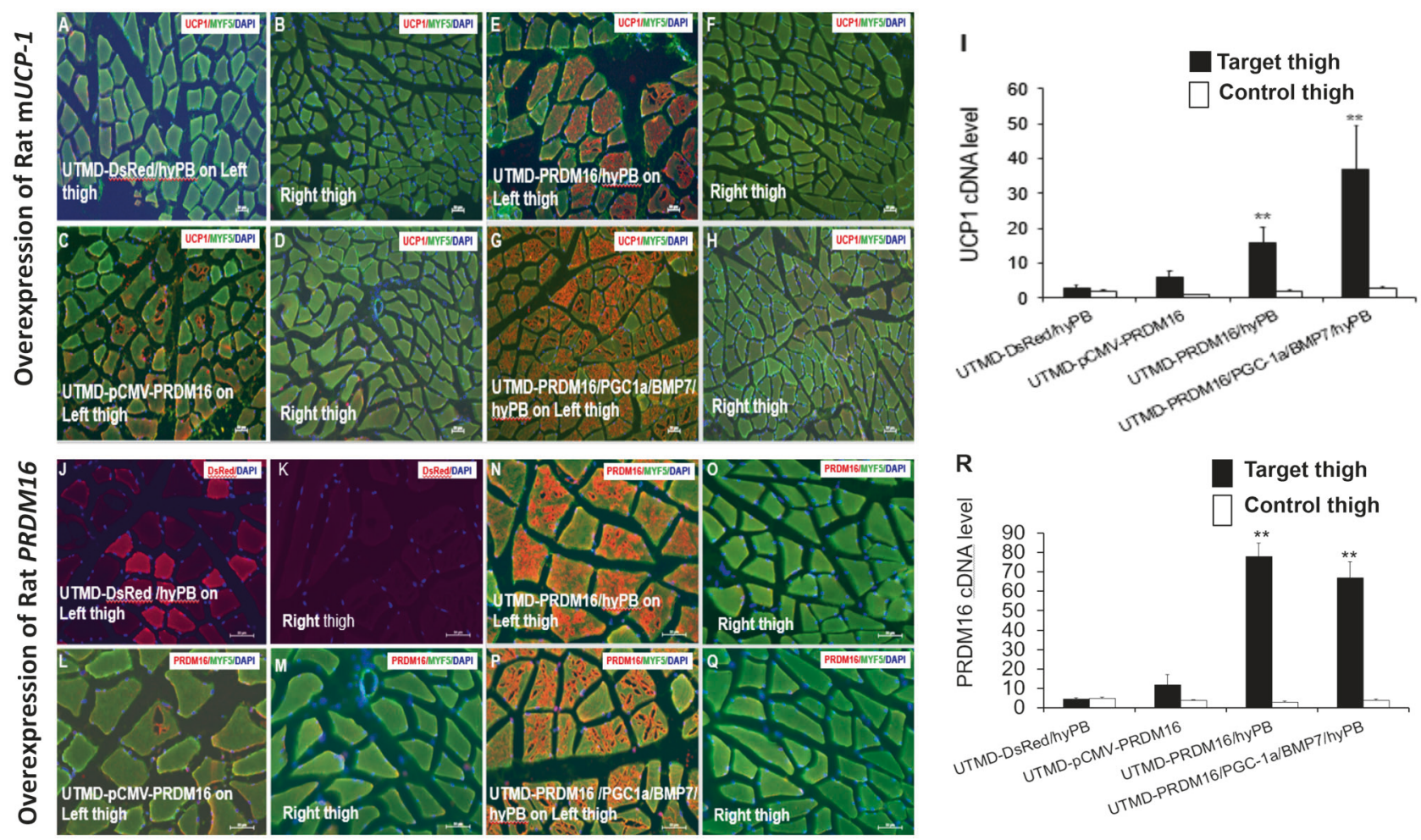

Fig. 3 Overexpression of $m U C P-1$ gene in adult rat skeletal muscle after UTMD treatment. a UTMD-DsRed/hyPB gene plasmids on left thigh. b Right thigh for control. c UTMD-pCMV-PRDM16 gene plasmids on left thigh. d Right thigh for control. e UTMD-PRDM16/ hyPB gene plasmids on left thigh. f Right thigh for control. $g$ UTMDPRDM16/PGC-1a/BMP7/hyPB plasmids on left thigh. h Right thigh for control. Scale bar is $50 \mu \mathrm{m}$. i A qRT-PCR for $m U C P-1$ cDNA level. Values are presented as mean \pm SEM. $n=6$ per group; $* * p<$ 0.001 vs control thighs or DsRed group. Overexpression of PRDM16 gene in adult rat skeletal muscle after UTMD gene delivery. $\mathbf{j}$ UTMD-

PRDM16 cDNA levels in treated thigh of WT mice or $m U C P-1-/-$ ko mice group after UTMD-pXL-BASII-CI$P R D M 16 /$ hyPB were $86 \pm 5$ and $81 \pm 7$-folds greater, respectively, than in thigh controls treated with UTMDDsRed/hyPB ( $p<0.001 ;$ Fig. $4 n)$.

\section{Perilipin A signal in SKM after UTMD gene delivery}

We further investigated if expression of perilipin A, an adipocyte-specific marker [25], was induced in the targeted SKM area. Figure 5 shows that a remarkable expression of perilipin A was only seen in WT mice but not in UCP-1-/knockout mice or DsRed mice after UTMD-pXL-CI$P R D M 16 /$ hyPB. A perilipin A signal was only identified in the treated left thigh from WT mice (Fig. 5c) but it was not seen in $m U C P-1-/-$ knockout mice and the right thigh controls (Fig. 5d, e), nor in the controls treated with UTMDDsRed reporter gene (Figs. 5a, b). qRT-PCR results show that Perilipin A cDNA levels in the treated thigh of the WT mice group after UTMD-pXL-BASII-CI- PRDM16/ hyPB was $66 \pm 5$-fold greater, than in right thigh controls
DsRed/hyPB gene plasmids on treated left thigh showing expression of the reporter gene (bright red signal); $\mathbf{k}$ same as panel $\mathbf{j}$ but on right thigh for control. I UTMD-pCMV-PRDM16 gene plasmids on left thigh. m Right thigh for control. n UTMD-PRDM16/hyPB gene plasmids on left thigh. o Right thigh for control. p UTMD-PRDM16/ $P G C-1 a / B M P 7 /$ hyPB plasmids on left thigh. q Right thigh for control. Scale bar is $50 \mu \mathrm{m}$. r A qRT-PCR for PRDM16 cDNA level. Values are presented as mean \pm SEM, $n=6$ per group; $* * p<0.001$ vs control thigh or DsRed group (color figure online)

$(p<0.001)$. There was no difference between the thigh treated with UTMD-DsRed/hyPB and thigh controls from the $m U C P-1-/-$ knockout mice group (Fig. 5m). Western blotting shows that the perilipin A signal in the treated left thigh of WT mice was significantly stronger than in $U C P$ 1-/- ko mice after UTMD-pXL-BASII-CI- PRDM16/hyPB gene delivery (Fig. 5r). Western blotting also shows that a significant mUCP-1 signal existed in treated left thigh of WT mice, but not in mUCP-1-/- ko mice after UTMDpXL-BASII-CI- PRDM16/hyPB gene delivery (Fig. 5r). Perilipin is an important regulator of lipid storage [26], so we further co-stained it with the neutral lipid dye oil red O [25]. We observed the stained lipid droplets in SKM. Figure 5i clearly shows that neutral lipid droplets and lipid droplet-associated protein (perilipin A) co-stained in the targeted SKM area but they are not seen in $m U C P-1-/-$ ko mice or right thigh controls (Fig. 5j, k), nor in the controls treated with UTMD-DsRed reporter gene (Fig. 5g, h). Figure 5o through $5 \mathrm{r}$ are magnified images (white square from panel I) clearly showing tiny lipid droplets in SKM cells. 

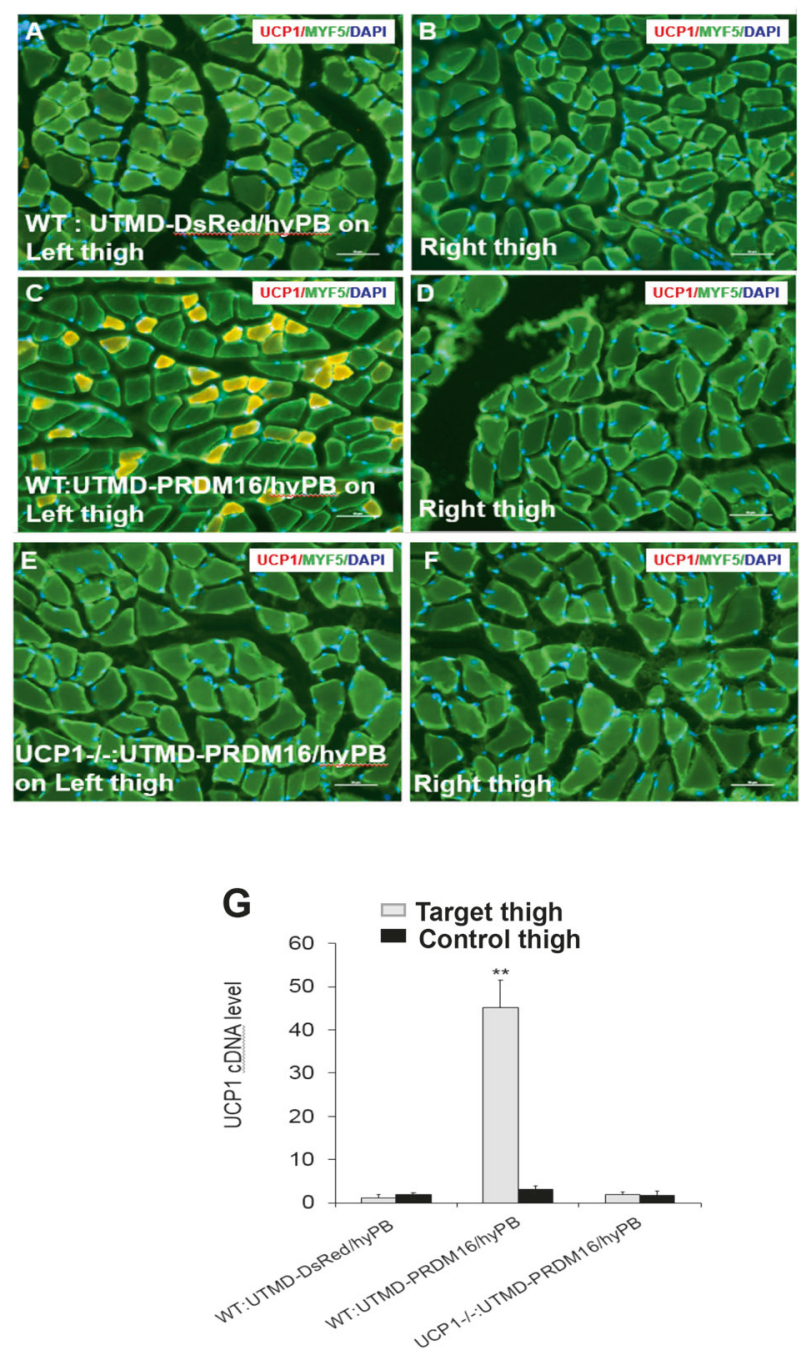

Fig. 4 Overexpression of mUCP-1 and PRMD16 gene in adult mice skeletal muscle after UTMD gene delivery. UCP1: a Wild-type mice: UTMD-DsRed/hyPB gene plasmids on left thigh. b Right thigh for control. c WT mice: UTMD-PRDM16/hyPB gene plasmids on left thigh. d Right thigh for control. e mUCP-1 -/- ko mice: UTMDPRDM16/hyPB plasmids on left thigh. f Right thigh for control. Scale bar is $50 \mu \mathrm{m}$. PRMD16: h Wild-type mice: UTMD-DsRed/hyPB gene plasmids on left thigh. i Right thigh for control. $\mathbf{j}$ WT mice: UTMD-

\section{Discussion}

In this study, we engineered overexpression of ectopic mUCP-1, which functions to dissipate energy as heat, in SKM of mice and rats through delivery of thermogenic BAT genes using non-viral, site-specific UTMD gene therapy, and replicate and expand upon previous findings [22]. In particular, we have generalized our previous findings in the Zucker fa/fa diabetic fatty (ZDF) [22] to different rodent strains: wild-type Sprague-Dawley rats $(N=24)$, wild-type C57BL/6 mice $(N=20)$ and heterozygous for $m U C P-1^{t m 1 K z}$ mice $(N=10)$.
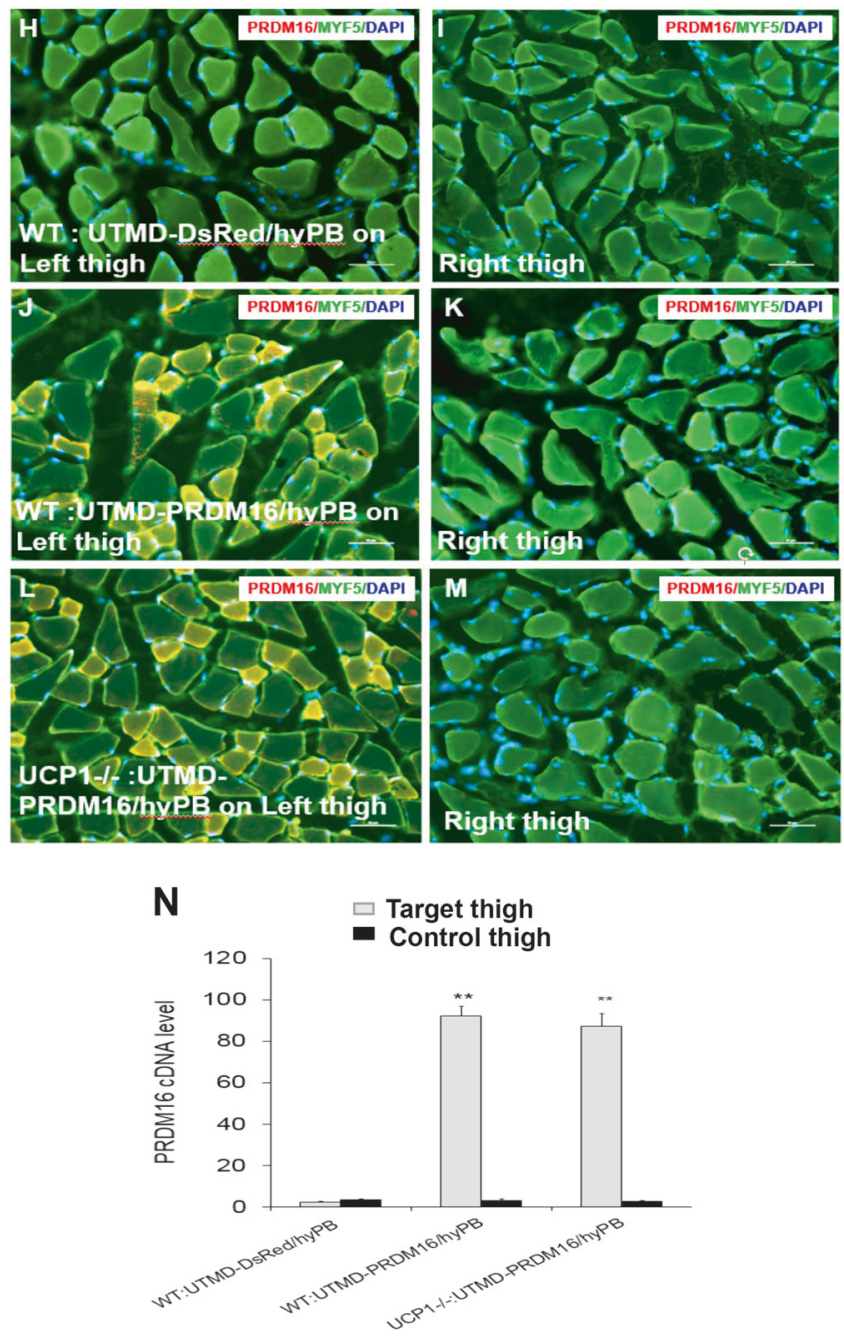

$P R D M 16 /$ hyPB gene plasmids on left thigh. k Right thigh for control. I $m U C P-1-/-$ ko mice: UTMD-PRDM16/hyPB plasmids on left thigh; m Right thigh for control. Scale bar is $50 \mu \mathrm{m}$. g A graphic for qRTPCR for $m U C P-1$ cDNA level. Values are presented as mean \pm SEM, $n=10$ per group; $* * p<0.001$ vs control groups. $\mathbf{n}$ A graphic for qRTPCR for PRDM16 cDNA level. Values are presented as mean \pm SEM. $n=10$ per group; $* * p<0.001$ vs control groups

\section{SKM as target for BAT induction}

"Brite", "beige", "inducible brown", or "recruitable brown" adipocytes [27] exist among white adipocytes and upon stimulation by chronic cold exposure (or other mechanisms that mimic beta-adrenergic stimulation) they become multilocular and begin expressing UCP1 [28]. WAT browning is stimulated by a complex hormonal interplay and numerous environmental factors such as prolonged cold exposure, $\beta$-adrenergic agonist treatment and exercise, and at the molecular level, it is regulated by multiple factors and signaling pathways. A key factor is Peroxisome proliferator- 

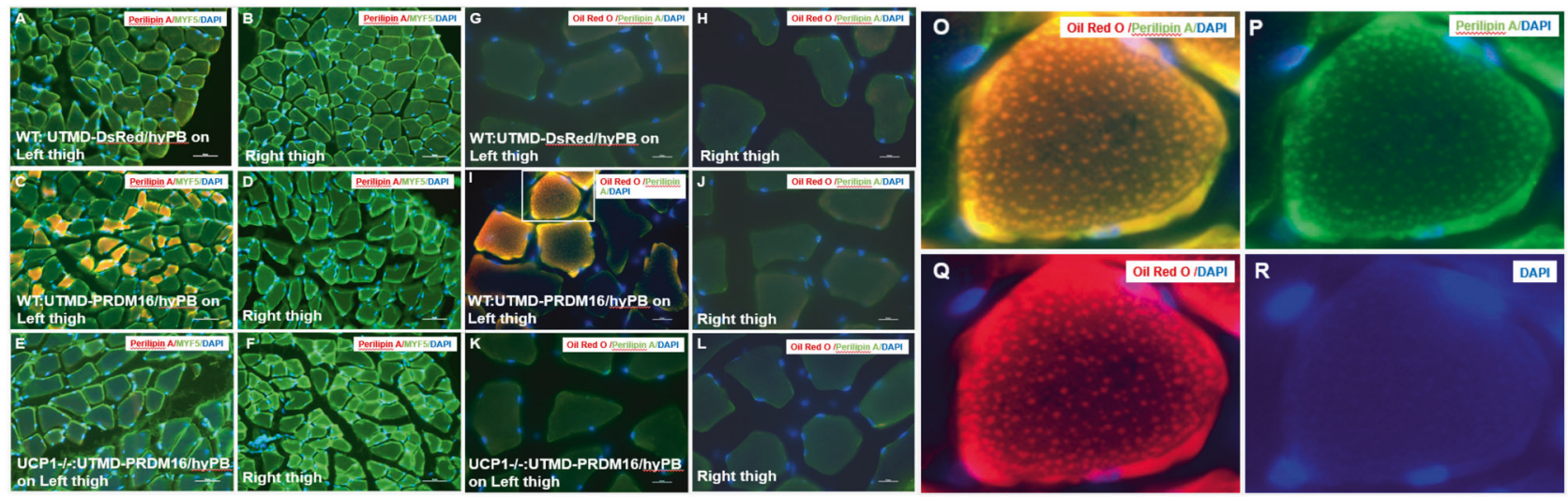

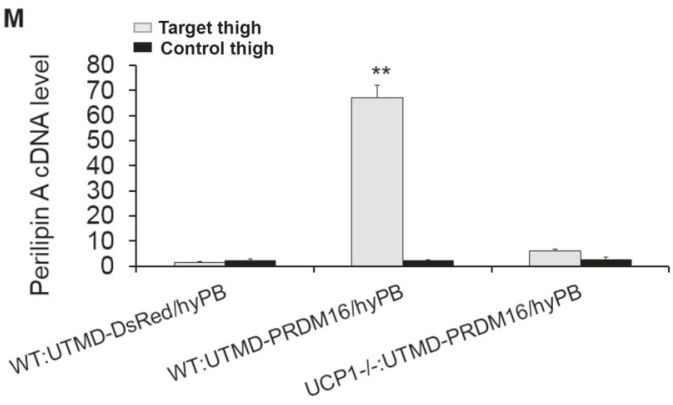

Fig. 5 Overexpression of brown adipose marker, perilipin A in adult mice skeletal muscle after UTMD gene delivery. a Wild-type mice: UTMD-DsRed/hyPB gene plasmids on left thigh. b Right thigh for control. c WT mice: UTMD-PRDM16/hyPB gene plasmids on left thigh. d Right thigh for control. e $m U C P-1$-/- ko mice: UTMDPRDM16/hyPB plasmids on left thigh. f Right thigh for control. Scale bar is $50 \mu \mathrm{m}$. Colocalization of adipose marker, perilipin A and the neutral lipid dye oil red $\mathrm{O}$ in adult mice skeletal muscle after UTMD gene delivery. $\mathrm{g}$ Wild-type mice: UTMD-DsRed/hyPB gene plasmids

activated receptor-gamma coactivator (PGC-1 $\alpha$ ) acting as master regulator of mitochondrial biogenesis and oxidative metabolism in adipocytes and inducing the expression of UCP1 [29]. Therefore, browning of WAT has attracted attention as a potentially important, efficient strategy to treat obesity and its related metabolic disorders. However, WAT has very few mitochondria and stores triglycerides in a single lipid droplet, whereas the BAT has an enormous number of mitochondria in depots that are highly innervated and vascularized [30]. Brown fat has a tremendous capacity to oxidize fatty acids and generate heat, due to the presence of its unique gene coding for the uncoupling protein $m U C P$ 1 [31]. In reality, BAT have striking similarities to SKM than WAT [21]. Indeed, the developmental origins of BAT and WAT are overall distinct, with brown adipocytes being derived from muscle precursors. Myf5-negative white adipocytes are derived from blood-vessel-associated pericytelike cells [32]. Unlike WAT, a common lineage for SKM and brown fat cells has been proposed arising from the dermomyotome. Both brown adipocytes and myocytes express myogenic factors such as Myf5 positive [33], and a
N

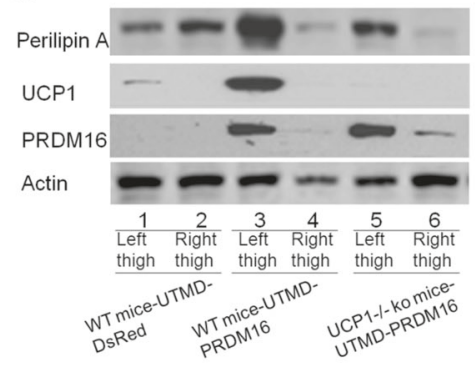

on left thigh. h Right thigh for control. i WT mice: UTMD-PRDM16/ hyPB gene plasmids on left thigh. $\mathbf{j}$ Right thigh for control. k $m U C P-1$-/- ko mice: UTMD-PRDM16/hyPB plasmids on left thigh. I Right thigh for control. Scale bar is $20 \mu \mathrm{m}$. o-r Magnified white square from panel I. $\mathbf{m}$ A graphic for qRT-PCR for perilipin A cDNA level. Values are presented as mean \pm SEM, $n=10$ per group; $* *<<$ 0.001 vs control groups. $\mathbf{n}$ Western blots detecting PRDM16, $m U C P$ 1 , and perilipin A proteins in skeletal muscle

strong correlation between BAT and SKM had already been recognized in gene expression profiling experiments indicating that they share similar mRNAs [34].

From an evolutionary perspective, BAT obtained the outstanding ability to develop thermogenic tissue of myogenic origin, to produce metabolic heat, to rapidly mobilize lipid droplets, and, very similar to SKM, to possess large amounts of mitochondria [35]. SKM and BAT seems to be complementary in their function. It is suggested that these organs maintain a functional crosstalk [36] and communicate with each other through myokines and adipokines during high metabolic demand including thermogenesis [37]. SKM is better vascularized compared with WAT. This was another important factor in choosing this tissue as our main target to deliver thermogenic BAT genes with the UTMD technique because high vascularity is a key determinant of BAT vs WAT destiny [38]. Therefore, some investigators currently consider BAT as a kind of specialized muscle [22]. One interesting hypothesis postulates that that SKM mitochondrial uncoupling drives endocrine crosstalk through the induction of myokine FGF21 released 
from SKM with endocrine effects leading to increased browning of WAT and can explain the healthy metabolic phenotype of UCP1-Tg mice [39]. PGC-1a is required for the expression of UCP1 in WAT and for the browning effect of FGF21 [40].

In vitro immunostaining (IHC) for cell markers is an indirect method of gene amplification allowing identification of the histological origin of the cell indicating its function in vivo when the correct antibody is used [41]. Overall, the IHC data from the treated left thigh of the rat model (Fig. 3) show qualitative positive results for the presence of mUCP-1 and PRMD16, compared with the negative staining from SKM of the right thigh. Particularly, Fig. $3 g$, p strikingly show robust cellular presence of mUCP-1 and PRMD16 immunoexpression in the treated thigh after delivering the UTMD-PRDM16/PGC-1a/BMP7/ hyPB gene cocktail. This IHC pattern for protein expression was followed by the mice group showing the presence of mUCP-1 and PRMD16 after the WT group received the PRDM16/hyPB gene therapy (Fig. 4c), also showing negative staining for UTMD-DsRed/hyPB or mUCP-1 in the $m U C P$-1-/- ko mice (Fig. 4a, e).

These IHC data were reinforced and corroborated by quantitative RT-PCR analysis measuring rat PRDM16 and mUCP-1 cDNA levels. RT-PCR-based analysis of DNA offer a precise quantitative analysis of gene amplification [42], adding sensitivity and specifity to our conventional IHC [43]. Following the results of the rat IHC data from Fig. 3, rat mUCP-1 and PRDM16 cDNA levels were significantly higher $(p<0.001)$ in the treated thigh after gene expression with piggybac transposon plasmids in our UTMD gene delivery system when compared with the gene expression with regular CMV or the controls treated with UTMD-DsRed reporter gene (Fig. 3i, r). Quantification of the mUCP-1 (Fig. 4g) showed high mUCP-1 levels in the WT but not in the $m U C P-1-/-$ ko mice treated with the PRDM16/hyPB gene therapy. These findings were confirmed with western blotting by measuring PRDM16 and mUCP-1 protein content in the mice biopsy samples after UTMD gene therapy corroborating that the changes in mRNA expression levels resulted in changes in protein content (Fig. 5n). As it is shown in Fig. 5, we corroborated these findings with IHC and molecular measurements (RTPCR and western blotting) of perilipin A, a specific marker of adipocytes including brown adipocytes [25], in the SKM of our treated rodents. We detected significant overexpression of perilipin A in SKM [44].

\section{Effects on food intake}

The food intake results (Fig. 1a, b) showed that the 30-day food intake pattern after gene therapy describes a tick markshaped $(\mathcal{V})$ diagram where the shape sharply falls within the first 3 days in our treated rats and WT or $m U C P-1-/-$ ko mice receiving UTMD gene therapy with either the PRDM16/hyPB or the PRDM16/PGC-1a/BMP7/hyPB gene cocktail. Both rat and mice treated groups gradually increased their daily food intake, practically recovering the intake levels previous to gene therapy by day 30 . These data show that the gene therapy to rats with either the PRDM16/ hyPB or the $P R D M 16 / P G C-1 a / B M P 7 /$ hyPB gene cocktail and WT mice treated with UTMD-PRDM16/hyPB gene delivery consistently reduce daily food intake for short term, also describing the association between the amounts of food consumption and UTMD-based gene administration in SKM. Figures 1c, d show that the rats and mice started the treatment with UTMD gene therapy weighing $\sim 550 \mathrm{~g}$ and $\sim 22 \mathrm{~g}$, respectively. The rat group intervened with the PRDM16/hyPB or the PRDM16/PGC-1a/BMP7/hyPB gene cocktail ended up weighing $~ 500 \mathrm{~g}$ compared with the rats receiving $\mathrm{pCMV-PRDM16}$ or UTMD-DsRed/hyPB, which ended up with a final weigh similar or higher to the one previous to the UTMD treatment $(\sim 600 \mathrm{~g})$. The rat weight change and subcutaneous (SQ) fat loss (fat thickness evaluated with US image) from the hyPB-treated rats also resulted in a far greater percentage from fat mass compared with pCMV rats or hyPB/DsRed controls (Fig. 2a, b). The WT or $m U C P-1-/-$ ko mice receiving the $P R D M 16 /$ hyPB or UTMD-DsRed/hyPB increased their body weight at the end of 30 days $(\sim 27 \mathrm{~g})$, also showing that the WT group receiving the $P R D M 16 /$ hyPB maintained a quasi-flat line without any significant increase or decrease weight for 30 days.

\section{Thermogenesis}

We used a new technique to measure BAT thermogenesis using infrared imaging following our UTMD gene therapy [23]. Figure 2c, d clearly show that in both rat and mice models there were an increase in body surface temperature observed using this method in the treated animals. The highest temperature elevation seems to have been achieved in rats with the administration of the UTMD-PRDM16/ $P G C$-1a/BMP7/hyPB gene cocktail. These results may indicate that the significant increased temperature was due to $m U C P$-1-mediated thermogenesis. These findings represent the first standardized use of infrared imaging to specifically detect $m U C P-1$ activity after UTMD gene therapy, indicating that infrared thermography specifically detects $m U C P$-1-mediated thermogenesis in vivo and metabolic heat production in SKM [24].

\section{Gene cocktail vs. single-gene therapy}

We examined whether the administration of a cocktail of three thermogenic BAT genes (PRDM16, BMP7, PGC1A) 
or single PRMD16 into SKM could show phenotypic differences and produce enhanced effects on measurements for body weight, body weight changes, daily food intake, surface thigh temperature measured with infrared technology, and abdominal subcutaneous fat thickness between triple compared with single-gene delivery. Our results may have offered a pattern indicating a fairly appropriate response to this query at this time. What we obtained was a much more positive and intense $m U C P-1$ and PRMD16 overexpression detected through IHC, and significantly higher expression levels of these genes measured by qRT-PCR, accurately localized in SKM surrounding the site of the thigh exposed to US implementation in the treated rats and mice as shown in Figs. 3 and 4 after UTMD administration with either triple delivery or single-gene therapy. These molecular observations nicely correlated with measurements by thermal infrared imaging showing a significant increase in surface temperature in the same SKM site (Fig. 2c, d).

Our data did not categorically answer if the administration of the gene cocktail has an advantage over the singlegene effects. The rat and mice body weight changes, abdominal SQ fat thickness and weight loss showed similar patterns in either the delivery with UTMD-PRDM16/PGC1a/BMP7/hyPB gene cocktail or single-gene therapy with the UTMD-PRDM16/hyPB. However, it seems that there are key data to suggest that the use of UTMD-based triple gene delivery is slightly more effective than single PRMD16 gene delivery. These data include the apparently higher expression of UCP-1 protein (Fig. $3 \mathrm{~g}$ vs. 3e) in the triple than in the single, strongly supported by the qRT-PCR measurements (Fig. 3i), and the temperature elevation observed in rats with the administration of the UTMDPRDM16/PGC-1a/BMP7/hyPB gene cocktail (Fig. 2c). A pertinent clarification is the rationale to utilize UTMDPRDM16/PGC-1a/BMP7/hyPB gene cocktail or singlegene therapy with the UTMD-PRDM16/hyPB. The justification for choosing the triple cDNA construct was to mimic in SKM the complete set of genes key for the control and transcriptional regulation of classic brown fat cell differentiation and activation. $B M P 7$ acts in an autocrine manner to induce brown committed (UCP1-neg) preadipocytes [45], also inducing the expression of PRDM16 [46], which promotes the differentiation of mature brown adipocytes and suppresses both the WAT and the myogenic differentiation pathway, leading to the expression of PGCl $\alpha$ [47], which highly activates the expression of the final cellular product, the brown adipocyte-specific gene $m U C P-1$, the hallmark of BAT, leading to metabolic heat production [48]. Given that PRDM16 functions as the BAT key regulator [49], we decided to compare the effects of this single gene vs the triple construct.

It is critically important to obtain higher $U C P 1$ overexpression levels. It would contribute to produce powerful clinically translated thermogenic effects and metabolic heat production on food intake and energy expenditure. This is what we achieved with the triple gene delivery: an energy gap [50] that accurately explains why the rats gradually recovered their food intake patterns by day 30 , when compared with the patterns they showed before gene therapy administration and to the food intake of their controls. The weight loss in the treated rats never recovered the levels observed in the controls in spite of food intake recovery (Fig. 1) [51]. Under the concept of an energy gap [52] of $\sim 50 \mathrm{~g}$ weight loss in 30 days, the treated rats did not regain their initial weight practically without a significant change in energy intake as Kcal/day. We did not observe an overwhelming energy gap in the mice in this study experiencing single PRMD gene delivery as we did in the rat model. Energy expenditure represented by thermogenesis is likely to explain the weight loss maintained in these rats regardless of food intake gradual recuperation, clearly indicating BAT $m U C P l$ over activity and metabolic heat production secondary to UTMD gene therapy in SKM [53]. This finding follows to a certain extent similar explanations for the efficacy of long-term weight loss achieved by bariatric surgery and its effectiveness to stimulate daily energy expenditure as the energy gap [54] for long-term maintenance with apparent scanty changes in daily energy intake [55]. The precise interpretation of the higher gene expression of UCP-1 protein shown in Fig. 3g, i, the temperature elevation in Fig. 2c, and the energy gap concept, may lead to support that short-term UTMD-based triple gene delivery is slightly more effective than single PRMD16 gene delivery. A question remains to be seen is if this UCP1 higher activity obtained with the triple gene delivery could have some significant advantage in long-term results. Obese patients have a tendency to regain the weight that they lose. If, in response to weight loss, one can steadily stimulate the classical BAT machinery and browning of WAT, it would help weight loss maintenance [56].

\section{Limitations}

Two study design limitations of our study were: (1) we did not measure classical BAT markers such as PGC1a, CIDEA, PRDM16, ZIC1, LHX8, UCP1, BMP7 [57]; and (2) we did not include in vivo energy expenditure data, or plate-based respirometry of SKM mitochondria, to show that ectopic expression of UCP1 in SKM is functional and contributes to energy metabolism. However, combining UTMD-based gene therapy and BAT are novel research fields still with a lot of gaps in the knowledge base that need to be filled. Our next step would be to build a stronger overall evidence base.

Our early research finding raise several important questions: (a) given the results obtained with perilipin A, are we 
ectopically differentiating myogenic precursors to fully differentiated brown fat adipocytes? (b) We have not yet analyzed whether these UCP-1-expressing cells express myocyte specific proteins such as MyoD, MyoGenin, MF20, and Dystrophin analyzed by IHC and pRT-PCR [58]. Therefore, do we characterize myocytes expressing brown fat markers or brown fat adipocytes in between myocytes? (c) Is the age of the animals relevant in the context of the pool of stem cells differentiating and the rate at which they commit to full differentiation as they would change with age? (d) Would this research strategy be successful in old animals? (e) Would the early hypophagia induced by PRDM16 gene delivery in the $m U C P-1-/-$ ko mice suggest that this effect is not determined by a brown fat phenotype? (f) How fast can UCP1 be induced after gene delivery? These queries would be addressed within the future directions of the research strategy. Also, assuming that the work of this project proceeds as planned, our next steps will be to determine the time course of production of $U C P-1$ following organ-specific gene therapy delivered via UTMD to SKM in a non-human primate model [19].

In summary, our study reaffirms the feasibility of UTMD gene-based therapy administration in SKM, by documenting the overexpression of ectopic $m U C P-1$ by IHC, RTPCR, and western blotting after delivery of the thermogenic BAT gene program. These findings suggest that the increased thermogenesis and weight loss were elicited by a single administration of UTMD-based transgenes, obtaining localized $m U C P-1$ overexpression in SKM. Our results ratify SKM as an important therapeutic target for endocrine regulation of whole body metabolism.

\section{Methods}

\section{Experimental rodents}

Animal studies were performed according to NIH recommendations and approved by our institutional animal research committee. All phenotypes and molecular techniques (IHC, RNA isolation and quantitative RT-PCR analysis, and western blotting) were measured in wild-type Sprague-Dawley male rats, wild-type $\left(U c p-1^{+/+}\right)$, and Ucp1-null $\left(U c p-1^{-/}\right)$mice. Protocol-1: Wild-type Sprague-Dawley male rats at average body weight of 250 $\mathrm{g}$ were purchased from Harlan Laboratories (Indianapolis, IN, USA), housed in a temperature-controlled environment maintained at $30{ }^{\circ} \mathrm{C}$ under a 12:12-h light-dark cycle. Protocol-2: Wild-type C57BL/6 mice and heterozygous for $m U C P-1^{t m I K z}$ mice were purchased from the Jackson Laboratory (Farmington, Connecticut) and bred to produce wild-type $\left(m U C P-1^{+/+}\right)$and $m U C P$-1-null $\left(m U C P-1^{-/-}\right)$ mice. Mice were bred and housed at an ambient temperature of $30^{\circ} \mathrm{C}$ to prevent thermal stress to the $m U C P-1^{-/-}$mice. All mice were housed in a temperature-controlled environment maintained at $30^{\circ} \mathrm{C}$ under a 12:12-h light-dark cycle. All measurements were conducted at similar times and dates. All in vivo rat and mice studies were performed at the Baylor Scott \& White Research Institute (BSWRI), Dallas, TX.

\section{Whole body weights and food intake}

Daily weight measurement was performed in the rodents with an Ohaus-Valor 3000 TREME scale. Animals were fed on high-fat diets $(45 \% \mathrm{Kcal}(24 \mathrm{~g} \mathrm{\%})$ fat; $35 \% \mathrm{Kcal}$ $(41 \mathrm{~g} \%)$ carbohydrate; $20 \% \mathrm{Kcal}(24 \mathrm{~g} \%)$ protein) (cat \# D12451, Research Diets Inc., New Brunswick, NJ) before performing UTMD gene delivery. Each animal was kept in individual cages and received the high-fat diet chow daily for 1 month before the study. Food intake was measured on a daily basis.

\section{Subcutaneous abdominal fat thickness measurement with US image}

The thickness of SQ adipose tissue was determined by US image at baseline, day 10 and day 30 post UTMD. An anatomical area was carefully defined on the left lateral wall of the abdomen. This area was clipped and a reading was obtained with an A-mode device using a S12 transducer with a resonant frequency of $12 \mathrm{MHz}$ (Sonos 5500, Philips Ultrasound, Bothell, WA). The thickness of the subcutaneous abdominal fat layer was then calculated immediately after ultrasonic investigation.

\section{Thermal imaging measurement}

Local temperature at both thighs through an infrared imaging technique [23] was measured at baseline, day 10 and day 30 post UTMD. All the rats and mice were euthanized 30 days after UTMD. Surface temperature of both thighs was recorded under anesthetized condition using an infrared digital thermographic camera (T660sc, emissivity of 0.98 , FLiR Systems) placed $20 \mathrm{~cm}$ above the animal. The camera has a thermal sensitivity of $\sim 0.1{ }^{\circ} \mathrm{C}$ and a spatial resolution of $640 \times 480$ pixels [24].

\section{Non-viral site-specific UTMD gene therapy}

Animals were anesthetized with intraperitoneal ketamine $(60 \mathrm{mg} / \mathrm{kg})$ and xylazine $(5 \mathrm{mg} / \mathrm{kg})$, and a polyethylene tube (PE 50 for rat, PE 10 for mouse Becton Dickinson, Franklin Lakes, TN, USA) was inserted into the right internal jugular vein by surgical cut down. The hyPB transposon donor plasmids and helper plasmids ratio was 5:1. In all, $1 \mathrm{ml}$ of 
microbubble suspension containing $2 \mathrm{mg}$ plasmids $(0.5 \mathrm{ml}$ diluted with $0.5 \mathrm{ml}$ phosphate-buffered solution (PBS)) for a rat or $100 \mu \mathrm{l}$ of microbubble suspension containing $200 \mu \mathrm{g}$ plasmids $(50 \mu$ l diluted with $50 \mu \mathrm{l}$ PBS) for each mouse were infused over 5 min via pump (Genie, Kent Scientific, Torrington, CT). During the infusion, US was directed to the left thigh using a commercially available US transducer (S3, Sonos 5500, Philips Ultrasound, Bothell, WA). US was then applied in ultraharmonic mode (transmit $1.3 \mathrm{MHz} /$ receive $3.6 \mathrm{MHz}$ ) at a mechanical index of 1.4. Four bursts of US were triggered to every fourth end-systole by electrocardiogram using a delay of $45-70 \mathrm{~ms}$ after the peak of the $\mathrm{R}$ wave. These settings have shown to be optimal for plasmid delivery by UTMD using this instrument [59]. Microbubble destruction was visually apparent in all animals. After UTMD, the jugular vein was tied off, the skin closed, and the animals allowed to recover. All animals were euthanized using an overdose of sodium pentobarbital $(120 \mathrm{mg} / \mathrm{kg})$. SKM tissue was collected from the left (treated) and right (control) thighs (vastus lateralis) in all animals. All samples were placed in weigh boats and delivered to the processing room by the surgical technicians immediately following collection.

\section{Manufacture of plasmid-containing lipid-stabilized microbubbles}

Lipid-stabilized microbubbles were prepared as described previously [60]. Briefly, a stock solution is prepared containing $270 \mathrm{mg}$ of 1,2-dipalmitoyl-Sn-glycero-3-phosphatidylcholine, (Sigma, St. Louis, MO), $30 \mathrm{mg}$ of 1,2dipalmitoyl-Sn-glycero-3- phosphatidylethanolamine, (Sigma, St. Louis, MO), and $1 \mathrm{~g}$ of glucose. These ingredients were dissolved in a boiling water bath for 20-30 min, with pipetting of contents up and down until no visible particles remain. This stock solution was stored at $4-8{ }^{\circ} \mathrm{C}$. Plasmid-containing microbubbles were prepared by mixing $2 \mathrm{mg}$ of dried plasmid with $50 \mu \mathrm{L}$ of lipofectamine 2000 (Invitrogen, Carlsbad, CA) and incubating at room temperature for $15 \mathrm{~min}$. This liposome/plasmid DNA mixture was added to $400 \mu \mathrm{L}$ of lipid stock solution, $50 \mu \mathrm{L}$ of pure glycerol, and $5 \mu \mathrm{L}$ of $10 \%$ albumin solution, mixed well with a pipette, and then placed in ice. Aliquots of 0.5 $\mathrm{mL}$ of this phospholipid-plasmid solution were placed in $1.5 \mathrm{~mL}$ clear vials; the air in the headspace of the vials was replaced with perfluoropropane gas (Air Products, Inc., Allentown, PA). Each vial was incubated at $4-8^{\circ} \mathrm{C}$ for $30 \mathrm{~min}$ and then mechanically shaken for $30 \mathrm{~s}$ by a dental amalgamator (VialmixTM, Bristol-Myers Squibb Medical Imaging, N. Billerica, MA). The mean diameter and concentration of the microbubbles in the upper layer were measured by a particle counter (Beckman Coulter Multisizer III).

\section{Plasmid cDNA constructs}

PRDM16 cDNA (Cat\#: 15503, Addgene Company, Cambridge, MA), PGC-1 $\alpha$ cDNA (Cat\#: 10974, Addgene), BMP7 cDNA (Cat\#: sc119058, OriGene Technologies), DsRed cDNA (Clontech Laboratories), were subcloned into PiggyBac transposon plasmids (pXL-BSII donor plasmid) provided by Dr. Fraser at the University of Notre Dame (Notre Dame, IN, USA) [61], and hyperactive piggyBac transposase helper plasmid was provided by Dr. Bradley at Wellcome Trust Sanger Institute (Cambridge, UK) [62]. Cloning, isolation, and purification of the plasmids were performed by standard procedures, and the PCR products were sequenced to confirm that no artefactual mutations were present.

\section{Immunohistochemistry}

Tissue samples were fixed in $10 \%$ formalin for $24 \mathrm{~h}$ and transferred into $70 \%$ alcohol for paraffin embedding and $4 \%$ paraformaldehyde and $20 \%$ sucrose overnight at $4{ }^{\circ} \mathrm{C}$ for frozen sections. Cryostat sections $5-8 \mu \mathrm{m}$ in thickness were further fixed with acetone $\left(-20^{\circ} \mathrm{C}\right)$ for $5 \mathrm{~min}$ and quenched for 5-20 min with $10 \mathrm{mM}$ glycine in PBS. Sections were then rinsed in PBS three times, and permeabilized with $0.5 \%$ Triton $\mathrm{X}-100$ in PBS for $15 \mathrm{~min}$. The primary antibodies (rabbit polyclonal $m U C P-1$ antibody, rabbit polyclonal PRDM16 antibody, mouse recombinant monoclonal Myf5 antibody (OriGene Technologies, Rockville, MD), and rabbit polyclonal perilipin A antibody (Abcam Inc., Cambridge, MA)), were added and incubated at $4{ }^{\circ} \mathrm{C}$ overnight. After washing with PBS three times for 5 min each time, the secondary antibody was added and incubated for $1 \mathrm{~h}$ at room temperature. DAPI (1:5000 dilutions) staining for $5 \mathrm{~min}$. Sections were rinsed three times with PBS for 5 min each time and then mounted. The neutral lipid dye oil red O (Sigma, St. Louis, MO) was used in combination with immunofluorescence [25]. Oil red O was applied to the sections for $5 \mathrm{~min}$ (following 5-min washes in

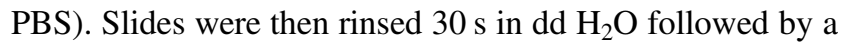
10-min wash under cold, slow running tap water. Coverslips were mounted to the dried slides using an anti-fade medium. All IHC presented in the results were representative of protein expression for both mice and rat samples.

\section{RNA isolation and quantitative RT-PCR analysis}

Total RNA was isolated from $50 \mathrm{mg}$ of SKM using the RNeasy mini kit (Qiagen). Real-time qRT-PCR analysis was performed on an ABI 7700 Sequence Detector (Applied Biosystems, Grand Island, NY, USA) using SYBR Green (RT2 SYBR Green qPCR Kit; Qiagen, Boston, MA, USA). Data were normalized to the expression of 
housekeeping genes (as an endogenous control). Changes in gene expression were normalized to control SKM samples. Primers were designed and synthesized by IDT Company.

\section{Western blotting}

Total protein extracts from skeletal tissue were evaluated with a Cytoplasmic and Nuclei Extraction Kit (Thermo Scientific, Rockford, IL, USA). Protein concentrations were determined using the BCA-200 Protein Assay kit (Pierce, Grand Island, NY, USA); equal amounts of protein were separated by sodium dodecyl sulfate-polyacrylamide gel electrophoresis to nitrocellulose membranes and incubated with primary antibodies included anti-PRDM16 (1:1000 dilutions), anti-mUCP-1 (1:2000 dilution), anti-perilipin A (1:2000 dilution), and anti-actin (1:2000 dilutions). Horseradish peroxidase secondary antibodies were used, and chemiluminescence was determined using the SuperSignal West Dura detection system (Pierce); Cytoplasmic marker (actin) was used to confirm equal loading. All western blots were performed in duplicate.

\section{Data analysis}

Data were analyzed using Statview software (SAS, Cary, NC, USA). The values are presented as mean \pm SEM. Differences were analyzed by repeated-measures ANOVA with Fisher's post hoc test and were considered significant at $p<$ 0.05 .

Author contributions All authors listed, have made substantial, direct, and intellectual contribution to the work, and approved it for publication. In particular: RAB conceived the rationale to use UTMD in muscle tissue to express BAT thermogenic genes. SC and RAB designed the experiment. SC, J-SS, and PH performed the experiments, contributed reagents/materials/analysis tools and designed the figures. RAB, EJN-G, and JWK wrote the introduction and analyzed the data; RAB, ER-A, and AL-N wrote the conclusions and performed literature review. JWK, RADF, and PAG are senior authors that proofread the manuscript and substantially contributed to the conclusions and study design.

\section{Compliance with ethical standards}

Conflict of interest The authors declare that they have no conflict of interest.

\section{References}

1. Ng M, Fleming T, Robinson M, Thomson B, Graetz N, Margono $\mathrm{C}$, et al. Global, regional, and national prevalence of overweight and obesity in children and adults during 1980-2013: a systematic analysis for the Global Burden of Disease Study 2013. Lancet (Lond, Engl). 2014;384:766-81.

2. Aslibekyan S, Garvey WT. Obesity: obesity and cardiometabolic disease - more than meets the eye. Nat Rev Endocrinol. 2017;13: $566-8$.
3. Ochner CN, Barrios DM, Lee CD, Pi-Sunyer FX. Biological mechanisms that promote weight regain following weight loss in obese humans. Physiol Behav. 2013;120:106-13.

4. Lagerros YT, Rossner S. Obesity management: what brings success? Ther Adv Gastroenterol. 2013;6:77-88.

5. Betz MJ, Enerback S. Targeting thermogenesis in brown fat and muscle to treat obesity and metabolic disease. Nat Rev Endocrinol. 2017;14:77-87.

6. Halpern B, Mancini MC, Halpern A. Brown adipose tissue: what have we learned since its recent identification in human adults. Arq Bras Endocrinol Metabol. 2014;58:889-99.

7. Spiegelman BM. Banting Lecture 2012: regulation of adipogenesis: toward new therapeutics for metabolic disease. Diabetes. 2013;62:1774-82.

8. Katterle Y, Keipert S, Hof J, Klaus S. Dissociation of obesity and insulin resistance in transgenic mice with skeletal muscle expression of uncoupling protein 1. Physiol Genom. 2008;32:352-9.

9. Voigt A, Katterle Y, Kahle M, Kluge R, Schurmann A, Joost HG, et al. Skeletal muscle mitochondrial uncoupling prevents diabetes but not obesity in NZO mice, a model for polygenic diabesity. Genes Nutr. 2015;10:57.

10. Keipert S, Voigt A, Klaus S. Dietary effects on body composition, glucose metabolism, and longevity are modulated by skeletal muscle mitochondrial uncoupling in mice. Aging Cell. 2011;10:122-36.

11. O'Neill SM, Hinkle C, Chen SJ, Sandhu A, Hovhannisyan R, Stephan S, et al. Targeting adipose tissue via systemic gene therapy. Gene Ther. 2014;21:653-61.

12. Lukashev AN, Zamyatnin AA Jr.. Viral vectors for gene therapy: current state and clinical perspectives. Biochem (Mosc). 2016;81:700-8.

13. Thomas CE, Ehrhardt A, Kay MA. Progress and problems with the use of viral vectors for gene therapy. Nat Rev Genet. 2003;4:346-58.

14. Chen ZY, Yang F, Lin Y, Zhang JS, Qiu RX, Jiang L, et al. New development and application of ultrasound targeted microbubble destruction in gene therapy and drug delivery. Curr Gene Ther. 2013;13:250-74.

15. Geis NA, Katus HA, Bekeredjian R. Microbubbles as a vehicle for gene and drug delivery: current clinical implications and future perspectives. Curr Pharm Des. 2012;18:2166-83.

16. Zhang L, Sun Z, Ren P, Lee RJ, Xiang G, Lv Q, et al. Ultrasoundtargeted microbubble destruction (UTMD) assisted delivery of shRNA against PHD2 into H9C2 cells. PLoS ONE. 2015;10: e0134629.

17. Chen S, Shimoda M, Chen J, Matsumoto S, Grayburn PA. Transient overexpression of cyclin D2/CDK4/GLP1 genes induces proliferation and differentiation of adult pancreatic progenitors and mediates islet regeneration. Cell Cycle (Georget, Tex). 2012;11:695-705.

18. Frost PA, Chen S, Mezzles MJ, Voruganti VS, Nava-Gonzalez EJ, Arriaga-Cazares HE, et al. Successful pharmaceutical-grade streptozotocin (STZ)-induced hyperglycemia in a conscious tethered baboon (Papio hamadryas) model. J Med Primatol. 2015;44:202-17.

19. Chen S, Bastarrachea RA, Roberts BJ, Voruganti VS, Frost PA, Nava-Gonzalez EJ, et al. Successful beta cells islet regeneration in streptozotocin-induced diabetic baboons using ultrasound-targeted microbubble gene therapy with cyclinD2/CDK4/GLP1. Cell Cycle (Georget, Tex). 2014;13:1145-51.

20. Vu V, Liu Y, Sen S, Xu A, Sweeney G. Delivery of adiponectin gene to skeletal muscle using ultrasound targeted microbubbles improves insulin sensitivity and whole body glucose homeostasis. Am J Physiol Endocrinol Metab. 2013;304:E168-75.

21. Farmer SR. Brown fat and skeletal muscle: unlikely cousins? Cell. 2008;134:726-7. 
22. Bastarrachea RA, Chen J, Kent JW Jr., Nava-Gonzalez EJ, Rodriguez-Ayala E, Daadi MM, et al. Engineering brown fat into skeletal muscle using ultrasound-targeted microbubble destruction gene delivery in obese Zucker rats: proof of concept design. IUBMB Life. 2017;69:745-55.

23. Crane JD, Mottillo EP, Farncombe TH, Morrison KM, Steinberg GR. A standardized infrared imaging technique that specifically detects UCP1-mediated thermogenesis in vivo. Mol Metab. 2014;3:490-4.

24. Jang C, Jalapu S, Thuzar M, Law PW, Jeavons S, Barclay JL, et al. Infrared thermography in the detection of brown adipose tissue in humans. Physiol Rep. 2014;2:e12167.

25. Strauss JA, Shaw CS, Bradley H, Wilson OJ, Dorval T, Pilling J, et al. Immunofluorescence microscopy of SNAP23 in human skeletal muscle reveals colocalization with plasma membrane, lipid droplets, and mitochondria. Physiol Rep. 2016;4:e12662.

26. Kimmel AR, Sztalryd C. Perilipin 5, a lipid droplet protein adapted to mitochondrial energy utilization. Curr Opin Lipidol. 2014;25:110-7.

27. Frontini A, Cinti S. Distribution and development of brown adipocytes in the murine and human adipose organ. Cell Metab. 2010;11:253-6.

28. Cinti S. Between brown and white: novel aspects of adipocyte differentiation. Ann Med. 2011;43:104-15.

29. Cui XB, Chen SY. White adipose tissue browning and obesity. J Biomed Res. 2016;31:1-2.

30. Christian M, Parker MG. The engineering of brown fat. J Mol Cell Biol. 2010 Feb;2:23-5.

31. Nicholls DG. The physiological regulation of uncoupling proteins. Biochim Biophys Acta. 2006;1757:459-66.

32. Tang W, Zeve D, Suh JM, Bosnakovski D, Kyba M, Hammer RE, et al. White fat progenitor cells reside in the adipose vasculature. Science. 2008;322:583-6.

33. Atit R, Sgaier SK, Mohamed OA, Taketo MM, Dufort D, Joyner $\mathrm{AL}$, et al. Beta-catenin activation is necessary and sufficient to specify the dorsal dermal fate in the mouse. Dev Biol. 2006;296:164-76.

34. Timmons JA, Wennmalm K, Larsson O, Walden TB, Lassmann $\mathrm{T}$, Petrovic N, et al. Myogenic gene expression signature establishes that brown and white adipocytes originate from distinct cell lineages. Proc Natl Acad Sci USA. 2007;104:4401-6.

35. Mezentseva NV, Kumaratilake JS, Newman SA. The brown adipocyte differentiation pathway in birds: an evolutionary road not taken. BMC Biol. 2008;6:17.

36. Rodriguez A, Becerril S, Ezquerro S, Mendez-Gimenez L, Fruhbeck G. Crosstalk between adipokines and myokines in fat browning. Acta Physiol (Oxf). 2017;219:362-81.

37. Li F, Li Y, Duan Y, Hu CA, Tang Y, Yin Y. Myokines and adipokines: involvement in the crosstalk between skeletal muscle and adipose tissue. Cytokine Growth Factor Rev. 2017;33:73-82.

38. Bach AD, Arkudas A, Tjiawi J, Polykandriotis E, Kneser U, Horch RE, et al. A new approach to tissue engineering of vascularized skeletal muscle. J Cell Mol Med. 2006;10:716-26.

39. Keipert S, Ost M, Johann K, Imber F, Jastroch M, van Schothorst $\mathrm{EM}$, et al. Skeletal muscle mitochondrial uncoupling drives endocrine cross-talk through the induction of FGF21 as a myokine. Am J Physiol Endocrinol Metab. 2014;306:E469-82.

40. Fisher FM, Kleiner S, Douris N, Fox EC, Mepani RJ, Verdeguer F, et al. FGF21 regulates PGC-1alpha and browning of white adipose tissues in adaptive thermogenesis. Genes Dev. 2012;26:271-81.

41. Matos LL, Trufelli DC, de Matos MG, da Silva Pinhal MA. Immunohistochemistry as an important tool in biomarkers detection and clinical practice. Biomark Insights. 2010;5:9-20.

42. Gjerdrum LM, Sorensen BS, Kjeldsen E, Sorensen FB, Nexo E, Hamilton-Dutoit S. Real-time quantitative PCR of microdissected paraffin-embedded breast carcinoma: an alternative method for HER-2/neu analysis. J Mol Diagn. 2004;6:42-51.
43. Nistor A, Watson PH, Pettigrew N, Tabiti K, Dawson A, Myal Y. Real-time PCR complements immunohistochemistry in the determination of HER-2/neu status in breast cancer. BMC Clin Pathol. 2006;6:2.

44. Sawada T, Miyoshi H, Shimada K, Suzuki A, Okamatsu-Ogura Y, Perfield JW, et al. Perilipin overexpression in white adipose tissue induces a brown fat-like phenotype. PLoS ONE. 2010;5:e14006.

45. Tseng YH, Kokkotou E, Schulz TJ, Huang TL, Winnay JN, Taniguchi CM, et al. New role of bone morphogenetic protein 7 in brown adipogenesis and energy expenditure. Nature. 2008;454: $1000-4$.

46. Kajimura S, Seale P, Kubota K, Lunsford E, Frangioni JV, Gygi $\mathrm{SP}$, et al. Initiation of myoblast to brown fat switch by a PRDM16-C/EBP-beta transcriptional complex. Nature. 2009;460:1154-8.

47. Ventura-Clapier R, Garnier A, Veksler V. Transcriptional control of mitochondrial biogenesis: the central role of PGC-1alpha. Cardiovasc Res. 2008;79:208-17.

48. Seale P. Transcriptional regulatory circuits controlling brown fat development and activation. Diabetes. 2015;64:2369-75.

49. Seale P, Kajimura S, Yang W, Chin S, Rohas LM, Uldry M, et al. Transcriptional control of brown fat determination by PRDM16. Cell Metab. 2007;6:38-54.

50. Hill JO, Peters JC, Wyatt HR. Using the energy gap to address obesity: a commentary. J Am Diet Assoc. 2009;109: 1848-53.

51. Melby CL, Paris HL, Foright RM, Peth J. Attenuating the biologic drive for weight regain following weight loss: must what goes down always go back up? Nutrients. 2017;9:468.

52. Schutz Y, Byrne NM, Dulloo A, Hills AP. Energy gap in the aetiology of body weight gain and obesity: a challenging concept with a complex evaluation and pitfalls. Obes Facts. 2014;7: $15-25$.

53. Dulloo AG. Explaining the failures of obesity therapy: willpower attenuation, target miscalculation or metabolic compensation? Int J Obes. 2012;36:1418-20. 2005

54. Dulloo AG. Translational issues in targeting brown adipose tissue thermogenesis for human obesity management. Ann N Y Acad Sci. 2013;1302:1-10.

55. Major GC, Doucet E, Trayhurn P, Astrup A, Tremblay A. Clinical significance of adaptive thermogenesis. Int J Obes. 2007;31: 204-12. 2005

56. Marlatt KL, Ravussin E. Brown adipose tissue: an update on recent findings. Curr Obes Rep. 2017;6:389-96.

57. Park A, Kim WK, Bae KH. Distinction of white, beige and brown adipocytes derived from mesenchymal stem cells. World J Stem Cells. 2014;6:33-42.

58. Wood WM, Etemad S, Yamamoto M, Goldhamer DJ. MyoDexpressing progenitors are essential for skeletal myogenesis and satellite cell development. Dev Biol. 2013;384:114-27.

59. Zhou Q, Brown J, Kanarek A, Rajagopal J, Melton DA. In vivo reprogramming of adult pancreatic exocrine cells to beta-cells. Nature. 2008;455:627-32.

60. Chen S, Shohet RV, Bekeredjian R, Frenkel P, Grayburn PA. Optimization of ultrasound parameters for cardiac gene delivery of adenoviral or plasmid deoxyribonucleic acid by ultrasoundtargeted microbubble destruction. J Am Coll Cardiol. 2003;42: 301-8.

61. Cary LC, Goebel M, Corsaro BG, Wang HG, Rosen E, Fraser MJ. Transposon mutagenesis of baculoviruses: analysis of Trichoplusia ni transposon IFP2 insertions within the FP-locus of nuclear polyhedrosis viruses. Virology. 1989;172:156-69.

62. Yusa K, Zhou L, Li MA, Bradley A, Craig NL. A hyperactive piggyBac transposase for mammalian applications. Proc Natl Acad Sci USA. 2011;108:1531-6. 